\title{
Development of a predictive model to determine micropollutant removal using granular activated carbon
}

\author{
D. J. de Ridder ${ }^{1}$, M. McConville ${ }^{1}$, A. R. D. Verliefde ${ }^{1,2,4}$, L. T. J. van der Aa ${ }^{1,3}$, S. G. J. Heijman ${ }^{1}$, \\ J. Q. J. C. Verberk ${ }^{1}$, L. C. Rietveld ${ }^{1,3}$, and J. C. van Dijk ${ }^{1}$ \\ ${ }^{1}$ Delft University of Technology, P.O. Box 5048, 2600 GA Delft, The Netherlands \\ ${ }^{2}$ UNESCO Centre for Membrane Science \& Technology, University of New South Wales, \\ NSW 2052, Sydney, Australia \\ ${ }^{3}$ Waternet, P.O. Box 94370, 1090 GJ, Amsterdam, The Netherlands \\ ${ }^{4}$ KWR Watercycle Research Institute, P.O. Box 1072, 3430BB Nieuwegein, The Netherlands
}

Received: 5 August 2009 - Published in Drink. Water Eng. Sci. Discuss.: 13 October 2009

Revised: 8 December 2009 - Accepted: 11 December 2009 - Published: 22 December 2009

\begin{abstract}
The occurrence of organic micropollutants in drinking water and its sources has opened up a field of study related to monitoring concentration levels in water sources, evaluating their toxicity and estimating their removal in drinking water treatment processes. Because a large number of organic micropollutants is currently present (although in relatively low concentrations) in drinking water sources, a method should be developed to select which micropollutants has to be evaluated with priority. In this paper, a screening model is presented that can predict solute removal by activated carbon, in ultrapure water and in natural water. Solute removal prediction is based on a combination of solute hydrophobicity (expressed as $\log D$, the $\mathrm{pH}$ corrected $\log K_{\text {ow }}$ ), solute charge and the carbon dose. Solute molecular weight was also considered as model input parameter, but this solute property appeared to relate insufficiently to solute removal.

Removal of negatively charged solutes by preloaded activated carbon was reduced while the removal of positively charged solutes was increased, compared with freshly regenerated activated carbon. Differences in charged solute removal by freshly regenerated activated carbon were small, indicating that charge interactions are an important mechanism in adsorption onto preloaded carbon. The predicted solute removal was within 20 removal-\% deviation of experimentally measured values for most solutes.
\end{abstract}

\section{Introduction}

Pesticides and industrial waste chemicals were detected in drinking water sources in the eighties (Cotruvo, 1985). Nowadays, trace concentrations of pharmaceuticals and personal care products have been found in water sources as well. Their toxicological relevance and removal in water treatment processes is currently being assessed (Jones, 2001; Snyder, 2008; Westerhoff, 2005). Organic micropollutants cover a huge array of solutes (Schwarzenbach et al., 2006), but only a limited selection of specific solutes can be experimentally investigated due to time and financial constraints. Selection criteria can be based on one or more of the following criteria (Verliefde, 2007):

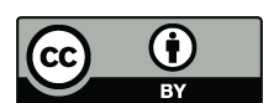

Correspondence to: D. J. de Ridder (d.j.deridder@tudelft.nl)
- Solute concentration level is high in drinking water sources;

- The solute poses a risk to human health;

- The solute has low removal in current drinking water treatment processes.

Health effects can be assessed by models that relate specific molecular properties to a projected toxicological endpoint, such as carcinogenity or mutagenity. These kind of models are referred to as Quantitative Structure Activity Relationship (QSAR) models, and are currently in use by environmental protection agencies (US EPA, Danish EPA) and in the European Union, in order to develop legislation related to water quality (Cronin et al., 2003).

Published by Copernicus Publications on behalf of the Delft University of Technology. 
Table 1. Selected compounds and their properties.

\begin{tabular}{|c|c|c|c|c|c|c|c|c|c|c|}
\hline & Solute & $\mathrm{pKa}$ & $\begin{array}{c}\text { MW } \\
(\mathrm{g} / \mathrm{mol})\end{array}$ & $\log K_{\mathrm{ow}}$ & $\begin{array}{r}\log D \\
(\mathrm{pH} 4)\end{array}$ & $\begin{array}{l}\text { Charged fraction } \\
(\%)\end{array}$ & $\begin{array}{r}\log D \\
(\mathrm{pH} 6.5)\end{array}$ & $\begin{array}{c}\text { Charged fraction } \\
(\%)\end{array}$ & $\begin{array}{r}\log D \\
(\mathrm{pH} 8)\end{array}$ & $\begin{array}{c}\text { Charged fraction } \\
(\%)\end{array}$ \\
\hline Negatively & Fenoprofen & 4.21 & 242.27 & 3.9 & 3.69 & 38.1 & 1.90 & 99.5 & 1.90 & 99.9 \\
\hline \multirow[t]{7}{*}{ Charged } & Clofibric acid & 3.35 & 214.65 & 2.57 & 1.83 & 81.7 & 0.57 & 99.9 & 0.57 & 99.9 \\
\hline & Ibuprofen & 4.47 & 206.29 & 3.97 & 3.84 & 25.3 & 1.97 & 99.1 & 1.97 & 99.9 \\
\hline & Ketoprofen & 4.29 & 254.28 & 3.12 & 2.94 & 33.9 & 1.12 & 99.4 & 1.12 & 99.9 \\
\hline & Diclofenac & 4.08 & 296.15 & 4.51 & 4.25 & 45.4 & 2.51 & 99.6 & 2.51 & 99.9 \\
\hline & Gemfibrozil & 4.45 & 250.34 & 4.77 & 4.64 & 26.2 & 2.72 & 99.1 & 2.77 & 99.9 \\
\hline & Bezafibrate & 3.44 & 361.82 & 4.25 & 3.58 & 78.4 & 2.25 & 99.9 & 2.25 & 99.9 \\
\hline & Naproxen & 4.84 & 230.59 & 3.18 & 3.12 & 12.6 & 1.51 & 97.8 & 1.18 & 99.9 \\
\hline \multirow[t]{5}{*}{ Neutral } & Phenazone & 1.3 (base) & 188.23 & 0.38 & 0.38 & 0.2 & 0.38 & 0 & 0.38 & 0 \\
\hline & Cyclophosphamide & $\mathrm{n} / \mathrm{a}$ & 261.09 & 0.63 & 0.63 & 0 & 0.63 & 0 & 0.63 & 0 \\
\hline & Aminopyrine & 4.9 (base) & 231.3 & 1 & $\mathrm{n} / \mathrm{a}$ & $\mathrm{n} / \mathrm{a}$ & 0.99 & 2.4 & 1 & 0.1 \\
\hline & Carbamazepine & 13.9 (acid) & 236.27 & 2.45 & 2.45 & 0 & 2.45 & 0 & 2.45 & 0 \\
\hline & Pentoxifylline & $\mathrm{n} / \mathrm{a}$ & 278.31 & 0.29 & 0.29 & 0 & 0.29 & 0 & 0.29 & 0 \\
\hline Positively & Terbutaline & 8.86 & 225.29 & 0.90 & -1.10 & 99.9 & -1.10 & 99.5 & -0.02 & 87.8 \\
\hline \multirow[t]{8}{*}{ Charged } & Propanolol & 9.58 & 259.35 & 3.48 & 1.48 & 99.9 & 1.48 & 99.9 & 1.89 & 97.4 \\
\hline & Sotalol & 9.44 & 272.38 & 0.24 & -1.76 & 99.9 & -1.76 & 99.9 & -1.22 & 96.5 \\
\hline & Salbutamol & 9.27 & 239.31 & 0.64 & -1.36 & 99.9 & -1.36 & 99.8 & -0.65 & 94.9 \\
\hline & Pindolol & 9.26 & 248.32 & 1.75 & -0.25 & 99.9 & -0.25 & 99.8 & 0.47 & 94.8 \\
\hline & Atenolol & 9.43 & 266.34 & 0.16 & -1.84 & 99.9 & -1.84 & 99.9 & -1.29 & 96.4 \\
\hline & Metoprolol & 9.49 & 267.37 & 1.88 & -0.12 & 99.9 & -0.12 & 99.9 & 0.38 & 96.8 \\
\hline & Clenbuterol & 9.29 & 277.19 & 2 & 0.00 & 99.9 & 0.00 & 99.8 & 0.69 & 95.1 \\
\hline & Aminopyrine & 4.9 (base) & 231.3 & 1 & 0.05 & 88.8 & $\mathrm{n} / \mathrm{a}$ & $\mathrm{n} / \mathrm{a}$ & $\mathrm{n} / \mathrm{a}$ & $\mathrm{n} / \mathrm{a}$ \\
\hline
\end{tabular}

No use of QSAR-models which predict solute removal in drinking water treatment has been reported, although some have been proposed for membrane filtration (Verliefde et al., 2009; Yangali-Quintanilla et al., 2008), ozonation (Lei and Snyder, 2007) and activated carbon filtration (Crittenden, 1999; Luehrs et al., 1996; Blum et al., 1994; C. Brasquet, 1997).

In this article, equilibrium removal data of 21 pharmaceuticals is presented. Their removal is predicted with a QSAR model for several process conditions: In ultrapure and surface water, and on both freshly regenerated and preloaded activated carbon.

\section{Materials and methods}

The pharmaceuticals were of analytical grade, and were obtained from Sigma-Aldrich. The selection of the pharmaceuticals was based on molecular weight (MW), charge (pKa) and hydrophobicity $(\log D)$ (see Table 1$)$.

$\mathrm{pKa}$ is the negative logarithm of the acidity constant $\left(K_{\mathrm{a}}\right)$, which is the equilibrium constant for solute dissociation or (de)protonation reaction. The relation between solute dissociation/protonation and $\mathrm{pH}$ is described by the HendersonHasselbalch equation, which is valid for monoprotic acids:

$\mathrm{pH}=\mathrm{pKa}-\log \frac{[\mathrm{AH}]}{\left[\mathrm{A}^{-}\right]}$

For bases, $[\mathrm{AH}]$ and $\left[\mathrm{A}^{-}\right]$can be replaced for $\left[\mathrm{AH}^{+}\right]$ and $[\mathrm{A}]$, respectively. When solution $\mathrm{pH}$ equals solute
$\mathrm{pKa}, 50 \%$ of the solutes are dissociated or protonated (i.e. $\left.\log [\mathrm{AH}] /\left[\mathrm{A}^{-}\right]=0\right)$. Nearly complete $(99 \%)$ dissociation or protonation is reached when $\mathrm{pH}$ value deviates $2 \mathrm{pH}$-units from the pKa value. In Table 1, it is shown that solute dissociation varies between $12 \%$ and $89 \%$ at $\mathrm{pH} 4$, and is $>97 \%$ for the other $\mathrm{pH}$ values. Solute protonation is $>87 \%$ at all $\mathrm{pH}$ values. Aminopyrine is a special case; in ultrapure water $(\mathrm{pH} 4)$ it is largely protonated, while it is largely neutral in surface water and waste water ( $\mathrm{pH} 8$ and 6.5 , respectively).

In the model, solute charge was represented by a simplified parameter which was -1 for negatively charged solutes, 0 for neutral solutes, and +1 for positively charged solutes. This parameter was multiplied with the charged solute fraction.

$\log D$ is a pH-dependent octanol water partition $\left(K_{\text {ow }}\right)$ and is relevant for solutes that are (partly) dissociated or protonated. It can be calculated using Eqs. (2) and (3).

Acids (negatively charged) $: \log D=\log K_{\mathrm{ow}}-\log \left(1+10^{(\mathrm{pH}-\mathrm{pKa})}\right)$

Bases (positively charged) : $\log D=\log K_{\text {ow }}-\log \left(1+10^{(\mathrm{pKa}-\mathrm{pH})}\right)$

It is assumed in these equations that $\log D$ values are highest for neutral solutes, and that this value decreases when solutes dissociate or protonate.

Three water types were used in the experiments: ultrapure water, surface water and wastewater effluent. Both surface water and wastewater samples came from treatment locations of Waternet, the watercycle company for Amsterdam and its surrounding areas. 
Table 2. Properties freshly regenerated NORIT GAC $830 \mathrm{P}$ (van Betuw et al., 2007).

\begin{tabular}{lll}
\hline Parameter & Unit & Value \\
\hline Iodine number & - & 1050 \\
Methylene blue adsorption & $\mathrm{g} / \mathrm{g}$ & 19 \\
Total surface area (BET) & $\mathrm{m}^{2} / \mathrm{g}$ & 1150 \\
Apparent density & $\mathrm{kg} / \mathrm{m}^{3}$ & 480 \\
\hline
\end{tabular}

The surface water originated from Weesperkarspel water treatment plant, after coagulation, filtration, ozonation and pellet softening pretreatment, and had a $\mathrm{pH}$ value of 8 . The wastewater originated from WWTP Horstermeer after primary sedimentation, activated sludge and secondary sedimentation and had an $\mathrm{pH}$ value of 6.5. Ultrapure water $(\mathrm{pH} 4)$ was produced from tap water, using activated carbon filtration, ion exchange and reverse osmosis.

The activated carbon used in the experiments was Norit GAC 830 P. Both freshly regenerated carbon and preloaded carbon were used. The preloaded carbon was collected from the full scale carbon filters at Weesperkarspel after a runtime of $>6$ months. The characteristics of fresh GAC $830 \mathrm{P}$ are given in Table 2. Before use, all carbon was sieved and the fraction $0.63-0.71 \mathrm{~mm}$ was collected. Fine particles were separated and removed from the carbon using sedimentation in ultrapure water. Finally, the carbon was dried at $105^{\circ} \mathrm{C}$ for $24 \mathrm{~h}$. Bottles, covers and stirring bars were rinsed three times with acetone and petroleum ether and dried in a stove at $105^{\circ} \mathrm{C}$.

Equilibrium removal was determined using adsorption isotherms. For each adsorption isotherm, seven bottles were prepared containing 20, 50, 100, 200, 500, 1000 and $2000 \mathrm{mg}$ of carbon. Ultrapure water was added and air trapped within the carbon pores was removed by boiling the samples for $2 \mathrm{~min}$. The remaining amount of water was determined by weight. Finally 2.251 of sample water was added to each bottle and the stock solution of pharmaceuticals was dosed, aiming at an initial concentration of $2 \mu \mathrm{g} / \mathrm{L}$ for all pharmaceuticals. The experiments were carried out in a climatised room at $12{ }^{\circ} \mathrm{C}$. Batch samples were continously stirred using a Labinco LD-746 magnetic stirrer at $84 \mathrm{rpm}$. This was the maximum rotation frequency at which carbon grains were still immobile, to prevent scouring of the grains. Samples were analyzed after 8 weeks.

When the samples were collected for analysis, they were filtered through a 0.45 micron cellulose acetate filter before they were analyzed at Technologiezentrum Wasser (TZW, Germany) using LC/MS/MS with SDB as solid phase eluent.

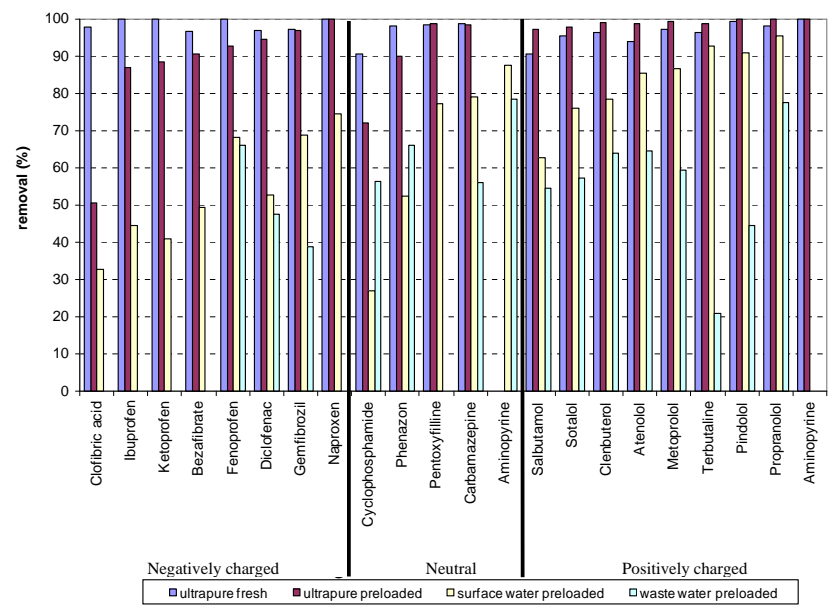

Figure 1. Solute removal at a carbon dose of $50 \mathrm{mg}$.

\section{Results and discussion}

\subsection{Results equilibrium experiments}

In ultrapure water, most solutes were removed $>95 \%$, even at carbon doses of $50 \mathrm{mg}$ (see Fig. 1). In surface water and wastewater, $>95 \%$ removal was achieved at carbon doses of $200 \mathrm{mg}$ and $1000 \mathrm{mg}$, respectively.

The solutes are ordered by increasing removal for each of the charge groups (negatively charged, neutral, positively charged). Figure 1 shows that in ultrapure water, removal of negatively charged solutes was reduced in the presence of a NOM preloading layer, while the removal of positively charged solutes increased. This difference can be explained by charge interactions. Although the $\mathrm{pH}_{\mathrm{pzc}}$ of fresh GAC $830 \mathrm{P}$ was not experimentally determined, or found in the literature, it is likely that GAC $830 \mathrm{P}$ was positively charged at $\mathrm{pH} 4$, as typical carbon $\mathrm{pH}_{\mathrm{pzc}}$ values are in the range 6-8 (Bjelopavlic et al., 1999). A positively charged carbon surface promotes removal of negatively charged solutes, and reduces removal of positively charged solutes.

NOM, on the other hand, is negatively charged at all experimental $\mathrm{pH}$ values (Newcombe, 1994). The presence of a NOM preloading layer on the preloaded carbons can mask the original carbon surface charge, and enhance removal of positively charged solutes and reduce removal of negatively charged solutes due to charge interactions. Removal of all 21 solutes on preloaded carbon was reduced in surface water as compared with ultrapure water, as a result of increased competition with NOM present in the water.

In wastewater, a high removal of five negatively charged solutes was observed in the blank sample, where no carbon was dosed. Consequently, their removal by activated carbon adsorption cannot be determined. This may indicate biological removal or adsorption onto suspended solids in the water phase. This last mechanism is unlikely; fenoprofen, diclofenac and gemfibrozil were not removed in the blank 
solution, while their $\log D$ values were similar to the other negatively charged solutes. Because of the limited amount of data left on removal of negatively charged solutes in wastewater, no further attempt has been made to construct a QSAR model to predict solute removal in this water matrix.

In order to estimate the influence of molecular weight and $\log D$ on solute removal, the correlation between solute equilibrium removal and each of these solute properties was investigated. The following was observed.

- At higher $\log D$ values, removal increased for solutes with similar charge. This can be related to increased hydrophobic partitioning due to lower water affinity.

- At similar $\log D$ values, positively charged solute are removed more efficiently then negatively charged solutes. On fresh carbon, these differences were relatively small. On preloaded carbon, however, neutral solutes show similar removal as negatively charged solutes, and positively charged solutes show 20-40\% higher removal. This indicated that charge attraction/repulsion is an important removal mechanism on preloaded carbon, and that the higher $\log D$ values of negatively charged solutes compensate charge repulsion enough to show similar removal as neutral solutes.

- MW showed poor correlation with solute removal. This can be related to the limited variation in MW in the solutes used, which varied between 200 and $300 \mathrm{~g} / \mathrm{mol}$ for most solutes. At similar MW, size exclusion effects and strengths of dispersion interactions will be similar and similar solute removal is expected based on MW alone. As such, MW cannot be used to explain differences in solute removal.

\subsection{QSAR development}

To predict solute equilibrium removal, a multivariable linear regression (MLR) model was developed. Different models were developed for each water type, using $\log D$, the solute charge parameter and carbon concentration as input parameters to predict solute removal. Carbon concentration did not have a linear relationship with solute removal. In order to linearize this relationship, the log carbon concentration was used. It has to be remarked that this linearized relationship is theoretically still not linear, but the data-entries are approximated well $\left(R^{2}>0.82\right)$.

In the model development, 17 solutes were used, while sotalol, propanolol, gemfibrozil and cyclophosphamide were reserved for model validation. The latter solutes were selected for model validation, as they represent the different charge groups and their log Kow values also vary.

\subsection{Model calibration and validation}

Individual models were constructed for ultrapure water and surface water, with either freshly regenerated or preloaded activated carbon. The model for solute removal on fresh carbon in ultrapure water was based on a smaller dataset $(n=30)$. As solutes were rapidly removed in this experimental condition, specific removal data was only available at lower carbon concentrations.

The following relations were found for each water type:

- Ultrapure water, fresh carbon $\mathrm{Ce} / \mathrm{C} 0=-0.019 \cdot \log D-0.029 \cdot$ charge $-0.284 \cdot \log \mathrm{CC}+0.46$ $N=34$, Max carbon concentration: $44.4 \mathrm{mg} / \mathrm{l}$

- Ultrapure water, preloaded carbon $\mathrm{Ce} / \mathrm{C} 0=-0.042 \cdot \log D-0.227 \cdot$ charge $-0.284 \cdot \log \mathrm{CC}+0.57$ $N=40$, Max carbon concentration: $44.4 \mathrm{mg} / \mathrm{l}$

- Surface water, preloaded carbon $\mathrm{Ce} / \mathrm{C} 0=-0.042 \cdot \log D-0.143 \cdot$ charge $-0.545 \cdot \log \mathrm{CC}+1.09$ $N=62$, Max carbon concentration: $88.9 \mathrm{mg} / \mathrm{l}$

CC: Carbon concentration

Solute removal increased at higher $\log D$ values and carbon concentrations. Negatively charged solutes are removed less effectively than positively charged solutes on preloaded carbon. On fresh carbon, the (relative) contribution of solute charge on the predicted removal is less than on preloaded carbon.

\subsection{Model performance}

Model acceptability can be determined using several criteria (Eriksson, 2003):

- dataset used to train the QSAR model contains at least 5 times more components than the amount of model variables used

- the dataset is representative (variable variation spans area of interest)

- the dataset is homogeneous (similar removal mechanisms)

- the model has "good performance". This can be expressed as $\mathrm{Q}^{2}$. To determine the $\mathrm{Q}^{2}$, parallel models are constructed with random data entries excluded from the training set. Consequently, the model is used to predict the value of the excluded data set, and the $R^{2}$ found for this data entry is the $\mathrm{Q}^{2}$. $\mathrm{A} \mathrm{Q}^{2}>0.5$ is regarded as good and a $\mathrm{Q}^{2}>0.9$ as excellent.

- The model gives random over/under prediction

According to the criteria of Eriksson, the amount of data is sufficient to construct a model (a minimum of 15 data entries is required for a 3-parameter model, which is achieved here). Solutes were selected to have a wide variety in solute parameters, each parameter representing a different removal 


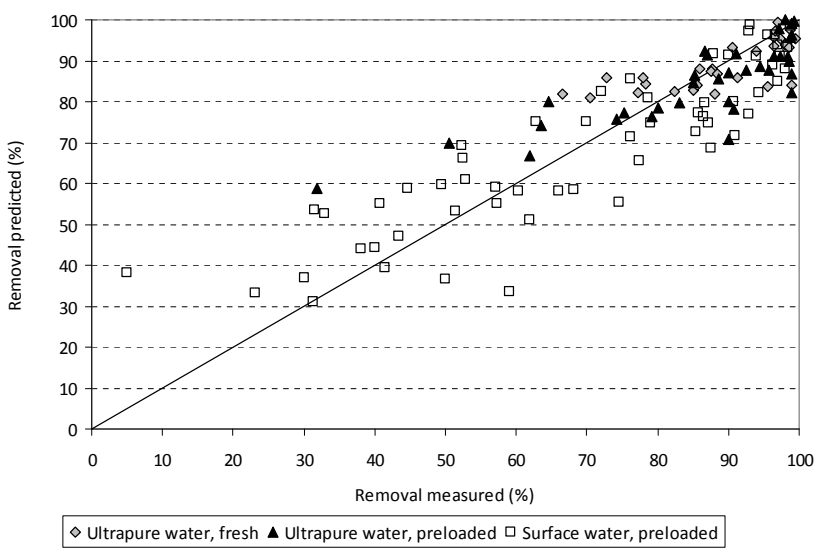

Figure 2a. Model performance for the training set. Ultrapure water, fresh carbon $-R^{2}=0.58 ; \mathrm{Q}_{\mathrm{loo}}^{2}=0.47$ Ultrapure water, preloaded carbon $-R^{2}=0.63 ; \mathrm{Q}_{\text {loo }}^{2}=0.50$ Surface water, preloaded carbon $-R^{2}=0.78 ; \mathrm{Q}_{\mathrm{loo}}^{2}=0.75$

mechanism (size exclusion, hydrophobic interaction, electrostatic attraction/repulsion). As a consequence, the dataset it representative, but cannot be homogeneous.

The model for fresh carbon in ultrapure water doesn't meet the criterion $\mathrm{Q}^{2}>0.5$. The model for preloaded carbon in ultrapure water just meets this criterion. However, both models were based on a rather limited dataset because of the high solute removal in ultrapure water, which may explain the sensitivity in model internal validation.

Predicted and measured removal rates are compared in Fig. $2 \mathrm{a}$ and $\mathrm{b}$, for the training set and the validation set, respectively. In all training sets, predicted solute removal is within 20 removal-\% deviation from measured solute removal for most solutes. However, larger deviations occur when predicting low solute removal $(0-35 \%)$, with overpredictions up to 30 removal- $\%$. As the database used in model construction contains only a few solutes with removal $<35 \%$, these solutes are not represented well when constructing the model using the least-squares fitting method, hence explaining the relatively large variations at low removal. In the (external) validation set shows, predicted removal values are mostly within 20 removal- $\%$ deviation of measured values, with over-predictions up to 40 removal- $\%$ at low solute removal. In all validation sets, cyclophosphamide removal was over-predicted at low carbon concentration. Possibly, this is related to the absence of aromatic rings in cyclophosphamide, and as such the inability to form pi-pi bonds with the carbon surface. All other solutes had aromatic rings in their molecular structure.

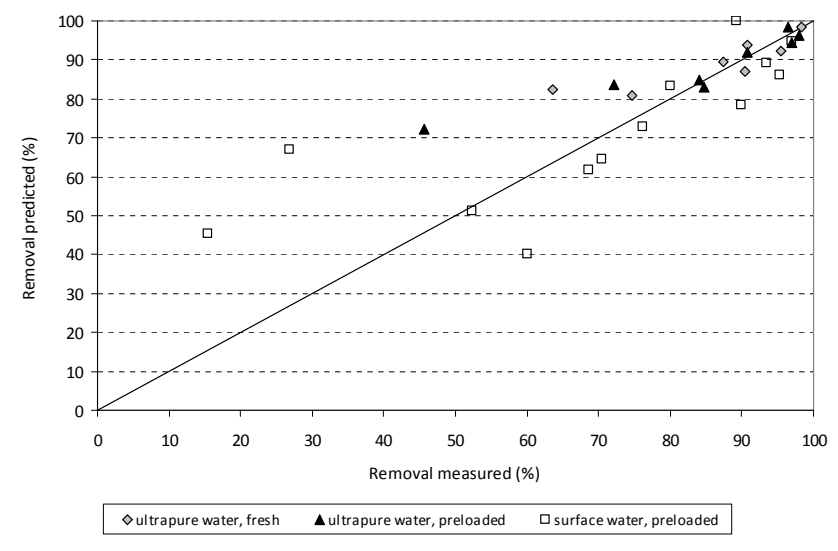

Figure 2b. Model performance for the validation set.

\section{Conclusions}

$\log D$ and solute charge were influential solute properties with respect to solute removal with activated carbon. Charge interactions appeared to be influential for charged solutes with preloaded carbon surface, but less influential for fresh carbon surface. When the activated carbon was preloaded with NOM, the carbon surface charge became negative, resulting in repulsive interaction with negatively charged solutes, and attractive interaction with positively charged solutes. In this dataset, solute molecular weight was not correlated with solute removal.

Acknowledgements. This paper is based upon work supported by VEWIN, the association of drinking water companies in the Netherlands. Any opinions, findings, conclusions, or recommendations expressed in this publication are those of the authors and do not necessarily reflect the views of the supporting organization.

Edited by: A. van der Helm

\section{References}

Bjelopavlic, M., Newcombe, G., and Hayes, R.: Adsorption of NOM onto activated carbon: effect of surface charge, ionic strength, and pore volume distribution, J. Colloid Interf. Sci., 210, 271-280, 1999.

Blum, D. J. W., Suffet, I. H., and Duguet, J. P.: Quantitative structure-activity relationship using molecular connectivity for the activated carbon adsorption of organic chemicals in water, Water Res., 28, 687-699, 1994.

Brasquet, P. L. C.: Adsorption onto activated carbon fibers: application to water and air treatments, Carbon, 35, 1307-1313, 1997.

Cotruvo, J. A.: Organic micropollutants in drinking water: an overview, Sci. Total Environ., 47, 7-26, 1985.

Crittenden, J. C., Sanongraj, S., Bulloch, J. L., Hand, D. W., Rogers, T. N., Speth, T. F., and Ulmer, M.: Correlation of aqueous-phase 
adsorption isotherms, Environ. Sci. Technol., 33, 2926-2933, 1999.

Cronin, M. T. D., Walker, J. D., Jaworska, J. S., Comber, M. H. I., Watts, C. D., and Worth, A. P.: Use of QSARs in international decision-making frameworks to predict ecologic effects and environmental fate of chemical substances, Environ. Health Persp., 111, 1376-1390, 2003.

Eriksson, L., Jaworska, J., Worth, A. P., Cronin, M. T. D., McDowell, R. M., and Gramatica, P.: Methods for reliability and uncertainty assessment and for applicability evaluations of classification- and regression-based QSARs, Environ. Health Persp., 111, 1361-1375, 2003.

Jones, O. A. H., Voulvoulis, N., and Lester, J. N.: Human pharmaceuticals in the aquatic environment: a review, Environ. Technol., 22, 1383-1394, 2001.

Lei, H. and Snyder, S. A.: 3D QSPR models for the removal of trace organic contaminants by ozone and free chlorine, Water Res., 41, 4051-4060, 2007.

Luehrs, D. C., Hickey, J. P., Nilsen, P. E., Godbole, K. A., and Rogers, T. N.: Linear solvation energy relationship of the limiting partition coefficient of organic solutes between water and activated carbon, Environ. Sci. Technol., 30, 143-152, 1996.

Newcombe, G.: Activated carbon and soluble humic substances: adsorption, desorption, and surface charge effects, J. Colloid Interf. Sci., 164, 452-462, 1994.
Schwarzenbach, R. P., Escher, B. I., Fenner, K., Hofstetter, T. B., Johnson, C. A., von Gunten, U., and Wehrli, B.: The challenge of micropollutants in aquatic systems, Science, 313, 1072-1077, 2006.

Snyder, S. A.: Occurrence, treatment and toxicological relevance of EDC's and pharmaceuticals in water, Ozone: Science \& Engineering, 30, 65-69, 2008.

Verliefde, A., Cornelissen, E., Amy, G., van der Bruggen, B., and van Dijk, H.: Priority organic micropollutants in water sources in Flanders and the Netherlands and assessment of removal possibilities with nanofiltration, Environ. Pollut., 146, 281-289, 2007.

Verliefde, A. R. D., Cornelissen, E. R., Heijman, S. G. J., Hoek, E. M. V., Amy, G. L., van der Bruggen, B., and van Dijk, J. C.: Influence of solute-membrane affinity on rejection of uncharged organic solutes by nanofiltration membranes, Environ. Sci. Technol., 43, 2400-2406, 2009.

Westerhoff, P., Yoon, Y., Snyder, S., and Wert, E.: Fate of endocrine-disruptor, pharmaceutical, and personal care product chemicals during simulated drinking water treatment processes, Environ. Sci. Technol., 39, 6649-4443, 2005.

Yangali-Quintanilla, V., Kim, T.-U., Kennedy, M., and Amy, G.: Modeling of RO/NF membrane rejections of PhACs and organic compounds: a statistical analysis, Drink. Water Eng. Sci., 1, 715,2008 , http://www.drink-water-eng-sci.net/1/7/2008/. 